\title{
Posterior uveitis: new insights provided by indocyanine green angiography
}

Indocyanine green (ICG) has been used routinely since 1957 outside ophthalmology, one indication being the measurement of cardiac output. It is a water-soluble dye of molecular weight of 775 that, after intravenous injection, is $98 \%$ protein bound. ${ }^{1}$ ICG absorbs light in the near-infrared wavelengths (peak absorption around $790 \mathrm{~nm}$ ) and emits peak photonic fluorescing energy at wavelengths around $830 \mathrm{~nm}$. Elimination occurs exclusively through the liver into the bile in a nonmetabolised form. ICG appears to be better tolerated than sodium fluorescein. CardioGreen (Becton Dickinson, Cockeysville, MD) contains 5\% iodide whereas Infracyanine (SERB, Paris, France) is devoid of iodide and can be used in patients with iodide allergy.

Indocyanine green angiography (ICGA) using venous injection of the dye has been performed in humans since $1973 .^{2}$ Poor resolution due to inadequate infrared cameras and infrared films and the lack of commercially available systems were major limitations that prevented routine and widespread use of this technique. It therefore remained in the hands of a few groups and retained an experimental character. In 1985, Bischoff and Flower ${ }^{3}$ reported their extensive experience with ICGA gained over a period of 10 years. Since the introduction of digitised imaging systems, ICGA has been the object of renewed interest. Indeed with the digitisation of the image and the use of improved infrared cameras the quality and the good reproducibility of images now allow their systematic analysis. ${ }^{46}$

Commercially available systems have led to the widespread use of ICGA, mainly in age-related macular degeneration. In this issue Howe and her colleagues analyse ICGA features in inflammatory eye disease - a potentially useful application of ICGA in ophthalmology. ${ }^{7-9}$

ICGA differs from fluorescein angiography in several ways that should be kept in mind when interpreting ICGA images. ICG fluoresces at $830 \mathrm{~nm}$ and therefore gives visual access to the choroidal vascular structures through the pigmentary epithelium. As stated by Howe et al. the molecular weight difference between ICG (775) and fluorescein (354) does not account for the particular angiographic pattern obtained with ICG compared with fluorescein. Besides the different wavelength at which ICG fluoresces, the crucial difference between these two fluorescing molecules results from their binding affinities to proteins (high for ICG and low for fluorescein). ${ }^{1}$ Non-protein-bound fluorescein leaks readily from slightly altered retinal vessels with minor damage to the blood-retinal barrier and readily impregnates tissues, but only major damage to retinal vessels such as in Behçet's uveitis allows the large ICG-protein complex to leak from retinal vessels. ${ }^{10}$ Very appropriately Howe et al. mention that ICG is not a reliable marker for retinal inflammation. Unlike in the retina, in the choroid protein-bound ICG leaks slowly but unimpaired from the fenestrated choriocapillaris, causing gradual impregnation of the choroid at the origin of the physiological choroidal background fluorescence. ${ }^{11,12}$ It is the alteration of this choroidal ICG impregnation, in the form of hypofluorescent areas produced by inflammatory lesions, that is the object of analysis in ICGA performed for posterior uveitis. As stated by Howe et al., most probably at least two mechanisms are at the origin of choroidal inflammatory hypofluorescent lesions: choriocapillaris non-perfusion and/or space-occupying inflammatory lesions in the choroidal stroma.

In order to interpret ICGA images correctly, standard early (up to $2 \mathrm{~min}$ ), intermediate ( \pm 10 $\mathrm{min}$ ) and late ( $\pm 40 \mathrm{~min}$ ) frames, and if possible follow-up angiograms, should ideally be available. Only in this way is it possible to categorise the inflammatory hypofluorescent lesions. ${ }^{13}$ Two main patterns of hypofluorescence have been determined: (1) Hypofluorescent areas are present at all phases of angiography due to choriocapillaris nonperfusion. ${ }^{14,15}$ Hypofluorescence can be either permanent as in atrophic lesions or reversible as in diseases affecting the choriocapillaris transiently such as multiple evanescent white dot syndrome (MEWDS), acute posterior multifocal placoid pigment epitheliopathy (APMPPE) or the hypofluorescent satellite dark dots seen around a focus of toxoplasmic Hôpital Ophtalmique Jules Gonin

Department of Ophthalmology University of Lausanne 15, Avenue de France $\mathrm{CH}-1004$ Lausanne Switzerland

Tel: +41216431515 Fax: +41216486010
C.P. Herbort, MD, PD 
retinochoroiditis. ${ }^{16-19}$ (2) In the second pattern hypofluorescent lesions present until the intermediate phase of ICGA tend to become isofluorescent or hyperfluorescent in the late phase. This pattern probably reflects the presence of space-occupying lesions beneath the choriocapillaris that delay normal ICG impregnation of the choroid. This pattern is seen mainly in granulomatous types of inflammation such as Vogt-Koyanagi-Harada disease, sympathetic ophthalmia, sarcoidosis, tuberculosis and some of the lesions seen in birdshot chorioretinopathy. ${ }^{20-22}$ Many of the latter type of hypofluorescent lesions respond to antiinflammatory or immunosuppressive therapy, indicating that they are active inflammatory lesions. In most diseases with the latter pattern of hypofluorescence, a concomitant diffuse hyperfluorescence is usually seen around the hypofluorescent lesions in the later phases of ICGA, reflecting leaking choroidal vessels, an element which is less prominent in disorders affecting primarily the choriocapillaris such as APMPPE and MEWDS. ${ }^{15,16}$

Because of the completely different physico-chemical properties of ICG, the pitfall of applying fluorescein interpretation schemes and terminology should be avoided. Abstraction should be made in most cases of the masking effect, which is such an important factor for the interpretation of fluorescein angiography. Infrared fluorescence can be seen through structures that are a screen for visible light, and therefore the masking effect has to be considered only if the interfering structures in front of the choroid are thick and/or heavily pigmented. In most cases of ICG hypofluorescent lesions it is therefore probably incorrect to speak of masking effect and it would more appropriate to speak of 'impaired choroidal fluorescence' or 'hindered choroidal ICGA diffusion'. Similarly, the notion of window defect does not usually intervene significantly for ICGA as the retinal pigment epithelium does not act as a screen as in fluorescein angiography.

Assessment of choroidal involvement in posterior uveitis has so far been limited. Because of the retinal pigment epithelium screen, fluorescein angiography gave only poor information, if any, on choroidal involvement, mainly showing chorioretinal atrophy. Ultrasound investigation was no better, being not sensitive enough to show small choroidal lesions that sometimes only affect the choriocapillaris. ICGA gives access for the first time to the choroid, and these new insights will most probably influence the appraisal and management of posterior uveitis. From the data Howe et al. and others have generated, it seems obvious that the amount of new information obtained from ICGA in posterior uveitis with suspected choroidopathy is such that posterior uveitis appears as one of the strongest indications and potentially most useful applications of ICGA in clinical practice. In future, more precise semiology in specific diseases and consequently the diagnostic value of ICGA will have to be determined. It will further have to be determined whether ICGA will be useful as a follow-up parameter and what its value will be for monitoring disease progression and effectiveness of therapy in posterior uveitis.

\section{References}

1. Baker KJ. Binding of sulfobromophthalein (BSP) sodium and indocyanine green (ICG) by plasma alpha-1 lipoproteins. Proc Soc Exp Biol Med 1966;122:957-63.

2. Lim JI, Flower RW. Indocyanine green angiography. Int Ophthalmol Clin 1995;35:59-70.

3. Bischoff PM, Flower RW. Ten years' experience with choroidal angiography using indocyanine green dye: a new routine examination or an epilogue? Doc Ophthalmol 1985;60:235-91.

4. Yannuzzi LA, Sorenson JA, Guyer DR, Slakter JS, Chang B, Orlock $\mathrm{D}$. Indocyanine green videoangiography: current status. Eur J Ophthalmol 1994;4:69-81.

5. Guyer DR, Yannuzzi LA, Slakter JS, Sorenson JA, Ho AC, Orlock D. Digital indocyanine green videoangiography of central serous chorioretinopathy. Arch Ophthalmol 1994;112:1057-62.

6. Yannuzzi LA, Hope-Ross M, Slakter JS, Guyer DR, Sorenson JA, Ho AC, et al. Analysis of vascularised pigment epithelial detachments using indocyanine green videoangiography. Retina 1994;14:99-113.

7. Howe L, Stanford M, Graham E, Marshall J. Indocyanine green angiography in inflammatory eye disease. Eye 1998;12:761-7.

8. Herbort CP, Borruat FX, de Courten C, Jaccard L. Angiographie au vert d'indocyanine dans les uvéites postérieures. Klin Monatsbl Augenheilkd 1996;208:321-6.

9. Slakter JS, Giovannini A, Yannuzzi LA, Sforzolini B, Guyer DR, Orlock DA. Indocyanine green videoangiography of multifocal choroiditis and the presumed ocular histoplasmosis syndrome. Invest Ophthalmol Vis Sci 1994:35:1982.

10. Guex-Crosier Y, Herbort CP. Prolonged retinal arteriovenous circulation time by fluorescein angiography but not by indocyanine green angiography in birdshot chorioretinopathy. Ocular Immunol Inflamm 1997;5:203-6.

11. Flower RW. Binding and extravasation of indocyanine green dye. Retina 1994;14:283-4.

12. Matsubara T, Uyama M, Takahashi K, Fukushima I, Tobe T, Matsunaga $\mathrm{H}$. Histological proof of localisation of indocyanine green in healthy choroid and retina and experimental choroidal neovascularisation. Invest Ophthalmol Vis Sci 1995;36:S243.

13. Herbort CP, LeHoang P, Guez-Crosier Y. Schematic interpretation of indocyanine green angiography in posterior uveitis using a standard angiographic protocol. Ophthalmology 1998;105:432-40.

14. Obana A, Kusumi M, Miki T. Indocyanine green angiographic aspects of multiple evanescent white dot syndrome. Retina 1996;16:97-104.

15. Howe LJ, Woon H, Graham EM, Fizke F, Bhandari A, Marshall J. Choroidal hypoperfusion in acute posterior placoid pigment epitheliopathy: an indocyanine green angiography study. Ophthalmology 1995;102:790-8.

16. Dhaliwal RS, Maguire AM, Flower RW, Arribas NP. Acute posterior multifocal placoid pigment epitheliopathy: an indocyanine green angiographic study. Retina 1993;13:317-25.

17. Borruat F-X, Auer C, Piguet B. Choroidopathy in multiple evanescent white dot syndrome. Arch Ophthalmol 1995;113:1569-71.

18. Auer C, Bernasconi O, Herbort CP. Toxoplasmic retinochoroiditis: new insights provided by indocyanine green angiography. Am J Ophthalmol 1997;123:131-3. 
19. Bernasconi O, Auer C, Herbort CP. Recurrent toxoplasmic retinochoroiditis: signification of perilesional satellite dark dots seen by indocyanine green angiography. Ocular Immunol Inflamm 1997;5:207-12.

20. Bernasconi O, Auer C, Zografos L, Herbort CP. Indocyanine green angiographic findings in sympathetic ophthalmia. Graefes Arch Clin Exp Ophthalmol 1998;236:635-8.
21. Oshima Y, Harino S, Hara Y, Tano Y. Indocyanine green angiographic findings in Vogt-Koyanagi-Harada disease. Am J Ophthalmol 1996;122:58-66.

22. Fardeau C, Herbort CP, Kullman N, Quentel GG, Cassoux N, LeHoang P. Use of indocyanine green (ICG) angiography in the assessment and follow-up of birdshot chorioretinopathy. Ophthalmology 1995:102(Suppl):138. 